www.jmscr.igmpublication.org

Index Copernicus Value: 79.54

ISSN (e)-2347-176x ISSN (p) 2455-0450

crossref DOI: https://dx.doi.org/10.18535/jmscr/v7i3.217

\title{
Management of hypotension during spinal anesthesia in pregnant patients using crystalloids and colloids without using any inotropes and vasoconstrictors
}

\author{
Authors \\ Javid Ahmad Dar*1, Abdul Hakeem ${ }^{2}$, Ubaid Ullah Gul Salmani ${ }^{3}$, Zahoor Ahmad Bhat ${ }^{4}$ \\ ${ }^{1,3,4}$ Senior Resident Department of Anesthesiology \& Critical Care, Govt. Medical College, Srinagar, India \\ ${ }^{2}$ AssociateProfessor, Department of Anesthesiology \& Critical Care, Govt. Medical College, Srinagar, India \\ *Corresponding Author \\ Dr. Javid Ahmad Dar \\ Resident, Department of Anesthesiology \& Critical Care, Govt. Medical College, Srinagar 190010
}

\begin{abstract}
Background: Prevention of hypotension during spinal anesthesia for cesarean section avoids maternal and fetal side effects. The aim of this study was Management of hypotension during spinal anesthesia in pregnant patients using crystalloids and colloids without using any inotropes and vasoconstrictors. Materials and Methods: In this prospective observational study 70 full term pregnant women aged between 20 to 30 years for elective lower segment caesarean section belonging to ASA-I and II class were randomly allocated equally to one of (CR Group) crystalloid or (CL Group) colloid groups.

Results: Hypotension occurred in the crystalloid Group, $51.4 \%$ compared with $28.5 \%$ in the colloid Group and the statistical difference between two groups was significant $(P=0.005)$. The incidence of nausea was \%11.42 (04 patients) in crystalloid group vs \% 17.14 (6 patients) in colloid group.

Conclusion: In conclusion, Prophylactic prehydration with colloid was more effective than prehydration with crystalloid for preventing hypotension in healthy parturient undergoing spinal anesthesia for elective cesarean delivery.

Keywords: Cesarean delivery, hypotension, spinal anesthesia, prehydration, crystalloids and colloids.
\end{abstract}

\section{Introduction}

Today Spinal anesthesia is utilized for practically any methodology beneath umbilicus. ${ }^{1}$ Spinal anesthesia, a standout amongst the most usually favored anesthesia types in the training, is utilized broadly, particularly in lower furthest point medical procedure, anorectal, urologic, obstetric, and gynecologic and bring down stomach surgery. ${ }^{2}$ Compared to general anesthesia Spinal anesthesia has diminished mortality, cardiovascular dreariness, profound venous thrombosis and aspiratory embolism, blood misfortune, span of medical procedure, torment, narcotic related unfavorable impacts, intellectual deformities, and length of emergency clinic remain. It is likewise realized that SA enhanced restoration contrasted and general anaesthesia. ${ }^{3,4}$

It has for some time been held that the overwhelming component of hypotension in the patient for Cesarean segment is caval 
compression. ${ }^{5}$ However medicines dependent on the caval pressure hypothesis have not demonstrated compelling and the standards behind this hypothesis have been tested in a genuinely ongoing editorial. ${ }^{6,7}$ This publication proposes that a decrease in blood vessel thoughtful tone is bound to be the predominant instrument of spinal hypotension, and this has consequently been upheld by studies which utilized nonstop heart yield screens amid spinal anesthesia. ${ }^{8,9}$ The run of the mill reaction to spinal anesthesia is in this way hypotension because of diminished fundamental vascular opposition and a resultant expanded heart rate, ${ }^{10}$ in spite of the fact that a little extent of patients may react with hypotension and bradycardia. ${ }^{11}$ It has additionally been noticed that pre-eclamptic patients are moderately impervious with the impacts of spinal anesthesia which a few creators propose is because of circling vasoconstrictors counterbalancing the impacts of the loss of blood vessel vascular tone. ${ }^{12,13}$ It has likewise been appeared expanded preoperative positional pulse change connects with an expanded rate of spinal hypotension and higher ephedrine requirements. ${ }^{14}$ The creators hypothesized that an expanded dimension of thoughtful movement was the component behind this marvel. A larger amount of preoperative tension has been appeared to be prescient of an expanded occurrence of hypotension under spinal anaesthesia. ${ }^{15}$

A few techniques have been proposed to decrease the occurrence, or relieve the seriousness, of hypotension, for example, quiet situating, liquid organization, and utilization of vasopressors to anticipate or address hypotension. ${ }^{16}$ The a decade ago has seen broad research endeavors to devise the ideal routine for aversion or treatment of spinal anesthesia-instigated hypotension, including sort of intravenous liquid (crystalloid or colloid), timing of liquid organization (previously or after commencement of spinal anesthesia), and decision of vasopressor (ephedrine or phenylephrine). ${ }^{17}$
The point of liquid imbuement is to kill the hypovolemia incited by spinal anesthesia, and for this reason, different liquids implantation conventions, including crystalloids and colloids, have been utilized for preloading before spinal anesthesia for cesarean segment. Numerous investigations have been accounted for the impacts of volume preload, utilizing different liquids, with various volumes and paces for treatment or aversion of hypotension instigated by spinal anesthesia. ${ }^{18-20}$

The point of this examination is to look at the impact of crystalloids and colloids in overseeing hypotension after spinal anesthesia in LSCS without utilizing any vasoconstrictor or ionotropics:

\section{Material \& Methods}

The present investigation was directed in the Tertiary consideration LD Hospital which is one of the related Hospital of Govt, Medical montage Srinagar from 2016 to 2017 for 70 full term pregnant ladies matured between 20 to 30 years for elective lower portion cesarean area having a place with ASA-I and II class. Parturients were haphazardly designated similarly to one of (CR Group) crystalloid or (CL Group) colloid gatherings.

Subsequent to getting endorsement from Institutional Ethical Committee, composed educated assent was gotten from every one of the patients previously medical procedure. Patients with any moderate to serious fundamental issue, patients reluctant to acknowledge territorial anesthesia, patients with any contraindication for spinal anesthesia, were prohibited from the investigation.

After landing in the working room and intravenous (IV) get to, was anchored then $500 \mathrm{ml}$ of ringer arrangement was injected inside 10-15 min before the commencement of the spinal square, likewise in the colloid aggregate $500 \mathrm{ml}$ of 6\% Hydroxyethyl starch arrangement was imbued to the patients. Spinal anesthesia was performed in the sitting position with a 25 measure whit acre 
needle, utilizing a midline approach at L4-5 interspace. When free stream of CSF had been perceived the intrathecal soporific arrangement (12 $\mathrm{mg}$ of $0.5 \%$ bupivacaine) was infused more than $15 \mathrm{~s}$, suctioning CSF toward the finish of infusion to affirm needle position. After intrathecal infusion, the patients were turned in prostrate position with left uterine relocation. Medical procedure was begun when a tactile square up to T5 dermatome was acquired.

All patients were then put prostrate and controlled oxygen by means of facemask. Amid the strategy an electrocardiogram, the pulse and heartbeat oximetry were observed constantly. Non-intrusive pulse was taken before the lead of spinal anesthesia and like clockwork after the intrathecal infusion until the finish of medical procedure. Hypotension was characterized as a decline in the mean blood vessel pulse, over $20 \%$ from benchmark inside a 5 min interim. Hypotension was treated with either liquid boluses or aliquots of intravenous mephatermin $6 \mathrm{mg}$ since the adequacy of mephatermin) was perceived in prior examinations. Bradycardia was characterized as pulse under 50 beats min- 1 and was treated with i.v. infusion of atropine $0.5-1 \mathrm{mg}$. Queasiness was characterized as the emotionally terrible sensation related with consciousness of the desire to upchuck. Heaving was characterized as the compelling removal of gastric substance from the mouth. The nature of anesthesia was surveyed by testing seriousness of intra agent torment utilizing Numerical VAS, where VAS 0 implied no torment and VAS 10 most exceedingly awful torment possible. VAS was assessed each $5 \mathrm{~min}$ from the season of skin cut until the finish of medical procedure. The utilization of VAS had recently been disclosed to every patient before medical procedure. VAS 1- 3 was considered as mellow agony, VAS 4- 6 as moderate, VAS 7, 8 as extreme and VAS 9, 10 as intolerable torment. Five minutes from that point, the VAS was evaluated. The stature of tactile square was likewise noted. The dimension of tactile square was dictated by the loss of pinprick sensation and was performed utilizing a $22 \mathrm{G}$ hypodermic needle. Tangible square dimension was tried like clockwork amid the initial 15-20 minutes after the intrathecal infusion. The specialist began all tasks 20 minutes after intrathecal infusion in each patient. No tangible testing was performed amid medical procedure.

\section{Statistical analysis}

Statistical test were performed using SPSS 11 for Windows. Results are reported as absolute value, mean \pm SD. Continuous variables were analyzed using Student's $\mathrm{T}$ test. Nominal or ordinal variables were analyzed by $\mathrm{Chi}$ square test and Fisher exact test or Mann-Whitney U test. $\mathrm{P}<0.05$ was considered statistically significant.

\section{Results}

Statistic qualities and benchmark factors in the two gatherings were practically identical. There was no factually critical contrast between two gatherings with respect to age, ASA class, weight,height and span of medical procedure table 1.

\begin{tabular}{|l|c|c|c|}
\hline \multicolumn{4}{|c|}{ Table 1. Comparison of Demographics Between Two Groups } \\
\hline VARIABLE & GROUP CR & GROUP CL & P value \\
\hline Age (years) & $25.55 \pm 5.90$ & $26.80 \pm 6.30$ & 0.70 \\
\hline WEIGHT & $61.50 \pm 8.87$ & $62.50 \pm 10.99$ & 0.82 \\
\hline HEIGHT & $166.3 \pm 4.6$ & $168.4 \pm 5.5$ & 0.876 \\
\hline ASAI/II & $28 / 7$ & $29 / 6$ & 0.754 \\
\hline DURATION OF SURGERY & $40.45 \pm 13.37$ & $42.11 \pm 14.82$ & 0.78 \\
\hline
\end{tabular}


Table-2: Intra Operative Systolic blood pressure

\begin{tabular}{|c|c|c|c|c|c|}
\hline Time & Group & Mean & SD & P-value & Remarks \\
\hline \multirow[t]{2}{*}{ Baseline } & CR & 119.55 & 4.651 & \multirow[b]{2}{*}{0.38} & \multirow[b]{2}{*}{ Not Sig } \\
\hline & CL & 120.75 & 3.193 & & \\
\hline \multirow[t]{2}{*}{ After Block } & CR & 119.05 & 3.193 & \multirow[b]{2}{*}{0.225} & \multirow[b]{2}{*}{ Not Sig } \\
\hline & CL & 119.65 & 2.033 & & \\
\hline \multirow[t]{2}{*}{5 min after Block } & CR & 105.25 & 1.05 & \multirow[b]{2}{*}{0.016} & \multirow[b]{2}{*}{ Sig } \\
\hline & CL & 119.75 & 3.15 & & \\
\hline \multirow[t]{2}{*}{30 min after Block } & CR & 90.02 & 1.00 & \multirow[b]{2}{*}{0.004} & \multirow[b]{2}{*}{ Sig } \\
\hline & CL & 119.15 & 3.00 & & \\
\hline \multirow[t]{2}{*}{60 min after Block } & CR & 85.60 & 0.75 & \multirow[b]{2}{*}{0.012} & \multirow[b]{2}{*}{ Sig } \\
\hline & CL & 120.67 & 3.10 & & \\
\hline \multirow[t]{2}{*}{ After Surgery } & CR & 115.35 & 1.35 & \multirow[b]{2}{*}{0.20} & \multirow[b]{2}{*}{ NS } \\
\hline & CL & 120.00 & 3.36 & & \\
\hline
\end{tabular}

The pattern estimations of mean systolic circulatory strain were similar between the gatherings with no factual criticalness. However, mean systolic circulatory strain esteems demonstrates statically critical distinction amid intra agent period between the gatherings The mean systolic pulse was observed to be bring down in patients of Group CR when contrasted with Group CL with $p$ estimation of $<0.05$ as appeared in table:2.

Table-3: Intra Operative Diastolic blood pressure:

\begin{tabular}{|c|c|c|c|c|c|}
\hline Time & Group & Mean & SD & P-value & Remarks \\
\hline \multirow[t]{2}{*}{ Baseline } & $\mathrm{CR}$ & 78.25 & 4.745 & \multirow[b]{2}{*}{0.336} & \multirow[b]{2}{*}{ Not Sig } \\
\hline & $\mathrm{CL}$ & 77.85 & 4.271 & & \\
\hline \multirow[t]{2}{*}{ After Block } & $\mathrm{CR}$ & 79.70 & 3.213 & \multirow[b]{2}{*}{0.335} & \multirow[b]{2}{*}{ Not Sig } \\
\hline & $\mathrm{CL}$ & 78.30 & 2.94 & & \\
\hline \multirow{2}{*}{5 min after Block } & $\mathrm{CR}$ & 62.65 & 2.75 & \multirow[b]{2}{*}{0.059} & \multirow[b]{2}{*}{ Sig } \\
\hline & $\mathrm{CL}$ & 77.10 & 3.25 & & \\
\hline \multirow[t]{2}{*}{30 min after Block } & $\mathrm{CR}$ & 58.25 & 1.75 & \multirow[b]{2}{*}{0.01} & \multirow[b]{2}{*}{ Sig } \\
\hline & $\mathrm{CL}$ & 78.30 & 3.75 & & \\
\hline \multirow[t]{2}{*}{$60 \mathrm{~min}$ after Block } & $\mathrm{CR}$ & 50.20 & 1.20 & \multirow[b]{2}{*}{0.015} & \multirow[b]{2}{*}{ Sig } \\
\hline & $\mathrm{CL}$ & 77.35 & 3.95 & & \\
\hline \multirow{2}{*}{ After Surgery } & $\mathrm{CR}$ & 69.70 & 3.10 & \multirow[b]{2}{*}{5.33} & \multirow[b]{2}{*}{ NS } \\
\hline & $\mathrm{CL}$ & 80.40 & 4.75 & & \\
\hline
\end{tabular}

The standard estimations of mean diastolic circulatory strain were equivalent between the gatherings with no measurable importance. In any case, mean diastolic pulse esteems indicates statically critical distinction amid intra agent period between the gatherings The mean diastolic circulatory strain was observed to be bring down in patients of Group CR when contrasted with Group CL with $p$ estimation of $<0.05$ as appeared table: 3 .

Table -4:-intra operative operative adverse effects

\begin{tabular}{|l|c|c|c|c|c|}
\hline Adverse effects & Group CR & $\%$ & Group CL & $\%$ & P-Vale \\
\hline Hypotension & 18 & $36 \%$ & 10 & $20 \%$ & $0.001(\mathrm{SIG})$ \\
\hline Bradycardia & 12 & $24 \%$ & 08 & $16 \%$ & $0.595(\mathrm{NS})$ \\
\hline Nausea & 11 & $22 \%$ & 09 & $18 \%$ & $0.873(\mathrm{NS})$ \\
\hline Vomiting & 03 & $6 \%$ & 1 & $2 \%$ & $0.804(\mathrm{NS})$ \\
\hline
\end{tabular}

The intraoperative unfriendly impacts saw among the two examination bunches just hypotension demonstrates statically huge esteem $(\mathrm{p}=0.001)$. At the point when different parameters were looked at measurably, the outcomes were found not critical with a $p$ estimation of $>0.05$ as appeared table: 4 . 


\section{Discussion}

Subarachnoid square is regularly utilized provincial analgesic system for patients who require careful anesthesia for lower furthest points, perineum, pelvic support or lower midregion. It might be valuable in patients with troublesome aviation route or experienced comorbidities of serious respiratory illness. Spinal anesthesia covering the mid-thoracic dimension yields a contracted small digestive tract to furnish unrivaled careful conditions in mix with significant muscle unwinding of stomach muscles. ${ }^{21}$

Spinal anesthesia for cesarean conveyance may cause extreme maternal hypotension, and a decline in cardiovascular yield and blood stream to the placenta. $^{22}$

Our investigation has appeared prophylactic prehydration with Hydroxyethyl starch was more viable than prehydration with crystalloid for avoiding hypotension in solid parturient experiencing spinal anesthesia for elective cesarean conveyance. We showed a higher frequency of hypotension in the crystalloid Group, $51.4 \%$ contrasted and $28.5 \%$ in the colloid Group $(\mathrm{p}=0.005)$.

Various examinations neglect to demonstrate constant circulatory strain support after prophylactic crystalloid administration. ${ }^{23,24}$ Blood weight and cardiovascular lists transitorily increment, yet these impacts are fleeting in light of the fact that crystalloid arrangements remain intravascular for just a restricted time. Liquid preloading with crystalloid is inadequate because of its fast redistribution. ${ }^{25}$

A well prehydration convention is known to increase intravascular volume, keep up stable hemodynamics parameters and enhance microcirculatory organ perfusion. A wide range of liquid conventions have been attempted by different examinations to limit the seriousness hypotension initiated by spinal anesthesia in obstetric patients and it appears that Colloid preload gives a supported increment in focal blood volume. $^{26.27}$
In our investigation, the gatherings were not altogether extraordinary, thinking about the general recurrence of queasiness, spewing, seriousness of sickness, and the recurrence of IV organization of atropine or metoclopramide. This was in concurrence with aftereffects of past studies. $^{28}$

Malthru et al found no hypotension when patients got $15 \mathrm{~mL} / \mathrm{kg}$ of $5 \%$ egg whites preceding spinal anesthesia for cesarean segment. The control gathering, which got $15 \mathrm{~mL} / \mathrm{kg}$ of $5 \%$ dextrose in LR, had a $29 \%$ frequency of hypotension. ${ }^{29}$

Sharma et al. as of late seen that patients given $500 \mathrm{~mL}$ of hetastarch had a $21 \%$ occurrence of hypotension after spinal anesthesia with lidocaine for baby blues tubal ligation contrasted with a $55 \%$ frequency in patients given $1000 \mathrm{~mL}$ of $\mathrm{LR}^{30}$

Extravascular redistribution of crystalloids might be rapid to the point that it might be difficult to implant them quick enough to keep up intravascular volume and evade hypotension amid spinal anesthesia. Colloid arrangements contain substantial atoms that don't quickly redistribute all through the extracellular liquid compartment. ${ }^{31}$

Our investigation showed that the most noteworthy decline in SBP in all gatherings happened $5 \mathrm{~min}$ after spinal anesthesia. This can be because of the affectability of the self-ruling sensory system and thoughtful loss of motion underneath the blockage site before tangible and engine loss of motion. In addition, in pregnant ladies, the hypotension can likewise be consequence of aortic and substandard vena cava pressure in prostrate position after spinal anesthesia. $^{32}$

Our investigation had a few constraints. The absence of a control gather blocked assurance of a flat out decrease in the rate of hypotension. For moral reasons, we could exclude a gathering without prehydration.

\section{References}

1. Goyal A, Shankaranarayan P, Ganapathi P. A randomized clinical study comparing 
spinal anesthesia with isobaric levobupivacaine with fentanyl and hyperbaric bupivacaine with fentanyl in elective cesarean sections. Anesth Essays Res 2015;9:57-62.

2. Wheatley RG, Schug SA, Watson D. Safety and efficacy of postoperative epidural analgesia. $\mathrm{Br}$ J Anaesth. 2001 Jul;87(1):47-61.

3. Rodgers A, Walker N, Schug S, McKee A, Kehlet H, van Zundert A, et al. Reduction of postoperative mortality and morbidity with epidural or spinal anaesthesia: results from overview of randomised trials. BMJ. 2000 Dec 16;321(7275):1493.

4. Macfarlane AJR, Prasad GA, Chan VWS, Brull R. Does regional anesthesia improve outcome after total knee arthroplasty? Clin Orthop. 2009 Sep;467(9):2379-402.

5. Holmes F. Collapse from spinal analgesia in pregnancy. Anaesthesia.1959;14:204.

6. Cyna AM, Andrew M, Emmett RS, Middleton P, Simmons SW Techniques for preventing hypotension during spinal anaesthesia for caesarean section. Cochrane Database Syst Rev. 2006; 4 CD002251.

7. Sharwood-Smith G, Drummond GB. Hypotension in obstetric spinal anaesthesia: a lesson from pre-eclampsia. Br J Anaesth. 2009;102:291-4.

8. Langesæter E, Rosseland LA, Stubhaug A. Continuous invasive blood pressure and cardiac output monitoring during cesarean delivery. Anesthesiology.2008;109:85663.

9. Dyer RA, Reed AR, van Dyk D, et al. Hemodynamic effects of ephedrine, phenylephrine, and the coadministration of phenylephrine with oxytocin during spinal anesthesia for elective cesarean delivery. Anesthesiology. 2009;111: 753-65.

10. Langesæter E, Dyer RA. Maternal haemodynamic changes during spinal anaesthesia for caesarean section. Curr Opin Anaesthesiol. 2011;24:242-8.

11. Kinsella SM, Lohmann G. Supine hypotensive syndrome. Obstet Gynecol. 1994;83:774-88.

12. Aya AG, Mangin $\mathrm{R}$, Vialles $\mathrm{N}$, et al. Patients with severe preeclampsia experience less hypotension during spinal anesthesia for elective cesarean delivery than healthy parturients: a prospective cohort comparison. Anesth Analg. 2003;97:867-72.

13. Clark VA, Sharwood-Smith GH, Stewart AV. Ephedrine requirements are reduced during spinal anaesthesia for caesarean section in preeclampsia. Int $\mathbf{J}$ Obstet Anesth. 2005;14:9-13.

14. Jeon YT, Hwang JW, Kim MH, et al. Positional blood pressure change and the risk of hypotension during spinal anesthesia for cesarean delivery. Anesth Analg. 2010;111:712-5.

15. Orbach-Zinger S, Ginosar Y, Elliston J, et al. Influence of preoperative anxiety on hypotension after spinal anaesthesia in women undergoing caesarean delivery. $\mathrm{Br}$ J Anaesth. 2012;109:943-9.

16. Cyna AM, Andrew M, Emmett RS, Middleton P, Simmons SW. Techniques for preventing hypotension during spinal anaesthesia for caesarean section. Cochrane Database Syst Rev 2006: CD002251

17. Dyer RA, Reed AR. Spinal hypotension during elective cesarean delivery: closer to a solution. Anesth Analg 2010; 111: 10935

18. Jabalameli M, Soltani HA, Hashemi J, Behdad S, Soleimani B. Prevention of post-spinal hypotension using crystalloid, colloid and ephedrine with three different combinations: A double blind randomized study. Adv Biomed Res. 2012;1:36. PMID: 23326767 
19. Marciniak A, Wujtewicz M, Owczuk R. The impact of colloid infusion prior to spinal anaesthesia for caesarean section on the condition of a newborn--a comparison of balanced and unbalanced hydroxyethyl starch 130/0.4. Anaesthesiol Intensive Ther. 2013 Jan-Mar;45(1):14-9. PMID: 23572302

20. Mitra JK, Roy J, Bhattacharyya P, Yunus M, Lyngdoh NM. Changing trends in the management of hypotension following spinal anesthesia in cesarean section. $\mathrm{J}$ Postgrad Med. 2013 Apr-Jun;59(2):121-6. PMID: 23793313.

21. Roussel JR, Heindel L (1999) Effect of intrathecal fentanyl on duration of bupivacaine spinal blockade for outpatient knee arthroscopy. AANA J 67(4): 337343.

22. McDonald S, Fernando R, Ashpole K, Columb M. Maternal cardiac output changes after crystalloid or colloid coload following spinal anesthesia for elective cesarean delivery: a randomized controlled trial. Anesth Analg. 2011 Oct;113(4):80310. PMID: 21890886

23. Mercier FJ. Fluid loading for cesarean delivery under spinal anesthesia: have we studied all the options? Anesth Analg. 2011 Oct;113(4):677-80. PMID: 21948275

24. Turker G, Yilmazlar T, Mogol EB, Gurbet A, Dizman S, Gunay H. The effects of colloid pre-loading on thromboelastography prior to caesarean delivery: hydroxyethyl starch 130/0.4 versus succinylated gelatine. J Int Med Res. 2011;39(1):143-9. PMID: 21672316

25. Singh J, Ranjit S, Shrestha S, Sharma R, Marahatta SB. Effect of preloading on hemodynamic of the patient undergoing surgery under spinal anaesthesia. Kathmandu Univ Med J (KUMJ). 2010 Apr- Jun;8(30):216-21. PMID: 21209539.
26. Mitra JK. Prevention of hypotension following spinal anaesthesia in caesarean section--then and now. Kathmandu Univ Med J (KUMJ). 2010 Oct-Dec;8(32):4159. PMID: 22610772

27. Kaya S, Karaman H, Erdogan H, Akyilmaz A, Turhanoglu S. Combined use of low-dose bupivacaine, colloid preload and wrapping of the legs for preventing hypotension in spinal anaesthesia for caesarean section. J Int Med Res. 2007 Sep-Oct;35(5):615-25. PMID: 17900401.

28. Lee A, Ngan Kee WD, Gin T. Prophylactic ephedrine prevents hypotension during spinal anesthesia for Cesarean delivery but does not improve neonatal outcome: A quantitative systematic review. Can J Anaesth 2002;49:588-99.

29. Mathru M, Rao TL, Kartha RK, Shanmugham M, Jacobs HK. Intravenous albumin administration for prevention of spinal hypotension during cesarean section. Anesth Analg. 1980 Sep;59(9):655-8. PMID: 7191222.

30. Riley ET, Cohen SE, Rubenstein AJ, Flanagan B. Prevention of Hypotension after Spinal Anesthesia for Cesarean Section: Six Percent Hetastarch Versus Lactated Ringer's Solution. Anesth Analg. 1995 Oct;81(4):838-42. PMID: 7574020

31. Davies P, French GW. A randomised trial comparing $5 \mathrm{~mL} / \mathrm{kg}$ and $10 \mathrm{~mL} / \mathrm{kg}$ of pentastarch as a volume preload before spinal anaesthesia for elective caesarean section. Int J Obstet Anesth. 2006 Oct;15(4):279-83. PMID: 16945514

32. Dahlgren G, Granath F, Wessel H, Irestedt L. Prediction of hypotension during spinal anesthesia for Cesarean section and its relation to the effect of crystalloid or colloid preload. Int $\mathbf{J}$ Obstet Anesth 2007;16:128-34. 